\title{
Comparative Psychological Research in East Asia: An Opportunity for East Asian Studies Scholars
}

\author{
Václav Linkov
}

\begin{abstract}
East Asian cultures are often labelled as 'collectivistic', 'dialectical' or 'Confucian' in comparative psychological research. This tendency is used to justify the generalisation of results found in one East Asian culture to all East Asian cultures and leads to an absence of psychological research comparing different East Asian cultures. In this paper I first show two examples of illdefined psychological constructs-Geert Hofstede's individualism and collectivism, and Richard E. Nisbett's and Peng Kaiping's dialectical thinking. Then I review the content of two main psychological journals with a focus on how often results from one East Asian culture are generalised to all East Asian cultures. Finally I offer a solution to the problem of neglected research comparing psychological differences among East Asian cultures. I state that lack of diversity in research teams and the under-representation of scholars from other than English-speaking countries in teams undertaking psychological research about East Asia contribute to this process. I suggest that East Asian scholars from non-English speaking countries should persuade psychologists from their universities to engage with East Asia.
\end{abstract}

Keywords: Comparative psychology, collectivism, dialectical self, East Asia

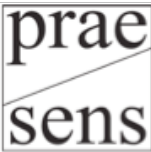

Linkov, Václav. "Comparative Psychological Research in East Asia: An Opportunity for East Asian Studies Scholars." In Vienna Journal of East Asian Studies, Volume 4, eds. Rudiger Frank, Ina Hein, Lukas Pokorny and Agnes Schick-Chen. Vienna: Praesens Verlag, 2013, pp. 51-65. https://doi.org/10.2478/vjeas-2013-0003 


\section{Introduction}

The second half of the 20th century saw the rise of universities in nearly all East $\operatorname{Asian}^{1}$ (EA) countries-Japan, South Korea, ${ }^{2}$ China and Taiwan - and many psychology departments now exist in all these countries. A full text search of PsycArticles - the database of journals published by the American Psychological Association-gives the following references by country: Japan (525 articles), China (415), India (200), Vietnam (177), Korea (162), Taiwan (135), Turkey (122), Arab countries (105), Iran (43), Thailand (37), Egypt (32), Indonesia (23), Nigeria (22) and Kenya (13). In the Journal of Cross-Cultural Psychology the corresponding results are: Japan (485 articles), China (350), India (268), Taiwan (189), Korea (174), Arab countries excluding Egypt (146), Turkey (143), Indonesia (86), Nigeria (77), Thailand (66), Kenya (65), Egypt (51), Iran (47) and Vietnam (41). More English-written psychological articles relate to EA than to any other region except Europe and North America. On the face of it, this is very good news for the East Asian Studies (EAS) scholar, who wants to learn something about psychological characteristics of East Asians. However, this expectation does not match with the reality of many published papers. In this paper I will explain why current psychological knowledge about EA cultures does not serve well the needs of EAS and how EAS scholars could help to improve this state of affairs.

Acknowledgements: I thank Cheng Tuan-Yao 鄭端耀, David Figures, Todd Hammond, Lukas Pokorny, Rudiger Frank and Tomáš Urbánek for their comments on this paper. While writing this paper I was a grantee of a Taiwan scholarship received from the Ministry of Education of the Republic of China.

1 By 'East Asia' I mean China, Japan, South and North Korea and Taiwan. By 'East Asian culture' I mean Chinese culture, Japanese culture or Korean culture. This text focuses on how these cultures are merged into one 'East Asian culture' in psychological research. Others articles could be written on how different cultures in China are merged into one 'Chinese culture' and, mutatis mutandis, how 'Korean culture' and 'Japanese culture' are fabricated in academic discourses. However, this is not the aim of this paper. For the purpose of this paper, I therefore (perhaps inaccurately) assume that there exists something like an aggregated Chinese culture, Korean culture and Japanese culture. In addition, I do not include Mongolia and Vietnam as a part of East Asia, for Mongolian or Vietnamese samples are not usually included in studies creating one 'East Asian culture' in psychological research. The term 'culture' itself could be interpreted in manifold ways. There has been much research done defining 'culture' in psychology. I will not repeat these discussions here. Various attempts to define the term 'culture' in psychological research are outlined, for example, in Jahoda (2012). For the purpose of this paper I define 'culture' as 'networks of knowledge consisting of learned routines of thinking, feeling, and interacting with other people, as well as a corpus of substantive assertions and ideas about aspects of the world...shared..., among a collection of interconnected individuals who are often demarcated by race, ethnicity, or nationality' (Hong 2009: 4).

2 When Korea or Korean is mentioned in this text, the terms always mean South Korea/South Korean. 


\section{Universal humans and universal Asians}

Psychologists often adopt 'operationalism' in defining constructs (Cappelli 2012). Theoretical constructs are operationalised through questionnaires developed from theory and then the construct is defined as being what was measured by these questionnaires. This produces 'circularity where a theoretical hypothesis points to an experimental result and vice versa' (Townsend 2008: 270). Acceptance of this kind of construct definition has led psychologists to accept (and to be tolerant of) confusing constructs and concepts. Tolerance to conceptual confusion can lead to insensitivity towards differences among people found through empirical research. Authors of psychological theories then claim that their theories are universal and apply them to all human beings - or to some particular groups of human beings - if it is not proven otherwise. The operationalist style of defining concepts in psychology has therefore led to the establishment of a kind of universal human being - the Universal Asian.

Psychologists often use undergraduate students as their subjects. ${ }^{3}$ In the United States, when psychologists report their results, they usually describe the percentage of students of different ethnic backgrounds in the sample. Often, the differences in results between these ethnic groups are reported. The operationalist way of defining constructs through test results then leads to defining the Universal Asian-a person who shares characteristics of people of Asian ethnicity as they were found by psychological research. This leads to the assumption that all Asians are virtually alike and that differences as such are marginal. Psychologists then use a group of American Asians or Asian students of different cultural backgrounds ${ }^{4}$ to define the characteristics of all Asians or use samples from one or two EA countries to describe the characteristics of all EA countries. EAS scholars, interested in differences between EA cultures, could not therefore use results from this kind of psychological research to describe any particular EA culture.

3 The practice of mainstream psychological research has its roots in the idea of falsificationism - the research is scientific as long as it is falsifiable. It is therefore a standard to use a group of people, watch them or give them some task to complete, and finally conclude that the result is valid for all humans - this conclusion is considered to be a scientific conclusion, because it could be falsified by finding people who behave differently. The easiest and cheapest way to get subjects for psychological research is to order students to become subjects. Many psychology departments (especially in North America) thus include participation as a subject in research as a compulsory part of undergraduate psychology education. This practice is sometimes criticised: 'Today more than ever, social psychology relies on student populations to complete surveys, respond to reaction time experiments, and participate in safe simulations with increasingly remote connections to real life. The triviality of the activities engaged in by research participants has led pundits to dub JPSP*, the leading journal in the area, as the Journal of Pretend Social Processes.' (Liu and Liu 1997: 165$66)$.

4 For example, Chentsova-Dutton and Tsai (2010: 509) compare European Americans with a sample of 30 Asian Americans, noting: 'Forty-Five percent of Asian Americans were Chinese and Taiwanese, 38 percent were Korean, 14 percent were Vietnamese, and 3 percent were Japanese.' 


\section{Universal collectivistic Asian}

The most influential concept in cross-cultural psychology, which helped to establish research that assumed all EA cultures to be the same, is Geert Hofstede's (1980) concept of individualism/collectivism. Hofstede made a survey research about work values in 63 countries and found four dimensions of intercultural difference in these values. These dimensions were later named as 'power distance', 'uncertainty avoidance', 'masculinity-femininity' and 'individualism-collectivism'. The first three have not been used as frequently as has the fourth, which became the most popular tool to distinguish cultures in psychology. Many studies using measures of individualism or collectivism were conducted in subsequent decades, often comparing some EA culture with some North American culture. People from EA cultures were often found to be more collectivistic in these comparisons and EA cultures were therefore labelled as 'collectivist cultures', which portrayed all East Asians in the same way. The explanation that EA cultures are 'collectivist' started to be used as a justification for research adopting the position that one EA culture is replaceable by another in psychological research. ${ }^{5}$

The problem here is that quantitative research would be able to catch differences between cultures only in the case where it was to include variables representing all important features of cultures. This is not possible for such a complex thing as a culture (Kim 2007), thus Hofstede's questionnaires with a limited number of questions asking only about work values and work environment from the perspective of a large American company (IBM) were not sophisticated enough for this task. Even if individualism/collectivism was a valid concept, the similarity of two cultures in terms of individualism/collectivism could not justify the opinion that it would also be similar in some other characteristics. Nevertheless, as will be illustrated below, the concept of individualism/collectivism does not seem to be logically consistent.

Problems with concepts of individualism and collectivism were found when differences between European Americans and other groups were analysed by Oyserman, Coon and Kemmelmeier (2002). Following the publication of Hofstede's work, they analysed scales and questionnaires that were used in research comparing individualism or collectivism between European Americans/Canadians and other groups of people. Some of these scales treated individualism and collectivism as a bipolar construct, whilst others deemed them as two constructs. Different scales for both constructs contained different items. Individualism scales contained seven types of items, namely, 'being independent and controlling one's own life', 'reach-

5 A recent example of this construction can be found in Yeung and Kashima (2012: 448): ‘...This suggests that during communication, people from individualistic cultures (e.g., Westerners) may prefer accuracy, while people from collectivistic cultures (e.g., Easterners) may prefer maintaining good relationships. ... Easterners (Chinese) tended to be more moderate (e.g., less punitive) than Westerners (Americans), reflecting that Easterners care about group harmony and integrity.' 
ing one's own goals', 'personal competition', 'being unique', 'having privacy', 'knowing oneself' and 'being able to directly communicate one's needs'. In contrast, collectivism scales contained eight types of items: 'considering close others as part of the self', 'wanting to belong to groups', 'feeling the obligations of being member of group', 'concern for group harmony', 'turning to others for advice', 'adapting oneself to context or situation', 'being focused on hierarchy' and 'preferring group work'.

Oyserman, Coon and Kemmelmeier analysed the differences in individualism and collectivism to be found between European Canadians/Americans and other groups according to the content of the questionnaires for countries, where the research about these differences was undertaken with more than one type of questionnaire. Among EA countries such research was available only for Hong Kong and Japan for individualism scales and Hong Kong, Japan, mainland China and Korea for collectivism scales. Americans were found more individualistic than Hong Kong Chinese, regardless of the content of the individualism scale. However, for Japan the result depended on the content of the scale:

\footnotetext{
Americans were higher in individualism than were Japanese when individualism assessment included personal uniqueness, valuing privacy, and direct communication. In fact, when individualism assessment did not include personal uniqueness, Americans were lower in individualism than were Japanese. ...When competition was included in the scale, the difference between American and Japanese in individualism disappeared (Oyserman, Coon and Kemmelmeier 2002: 16).
}

Oyserman, Coon and Kemmelmeier found the comparison results dependent on the content of the scale for collectivism as well: Americans were lower in collectivism than Hong Kong Chinese if the scale contained items concerning group harmony, defining the self in context and valuing hierarchy. When 'belonging to one's ingroups' was included or 'defining oneself in context' excluded from the scales, Americans were higher in collectivism than Hong Kong Chinese. Japanese were higher in collectivism than Americans if collectivism scales contained a preference for working in groups and Americans higher than Japanese if the questionnaire did not contain these questions. Koreans were higher in collectivism than Americans if the questionnaire included 'relatedness', whilst Americans were higher than Koreans otherwise. Mainland Chinese were more collectivistic than Americans irrespective of the content of the scale. However, if 'maintaining group harmony' was included, the difference was much larger than otherwise.

The results from Oyserman, Coon and Kemmelmeier demonstrate that a single construct of collectivism that will allow marking EA cultures as collectivistic does not exist. Several other more detailed constructs should replace collectivism and each culture should be studied independently from the others. However, even when concepts of individualism and collectivism had been the subject of a critique (e.g., 
by Fiske 2002), Oyserman, Kemmelmeier and Coon (2002) suggested that they are still useful and should be used further. Individualism and collectivism are still the most influential constructs in cross-cultural psychological comparison, and research comparison of different EA cultures - all marked as collectivistic - is therefore considered less interesting than it would be if individualism and collectivism were replaced by a larger number of more specific constructs.

\section{Universal dialectical Asian}

Following Kaiping Peng and Richard Nisbett's (1999) article, which analysed American and Chinese preferences for perception of social conflicts from both sides and dialectical proverbs, a new concept of 'dialectical thinking' is developing in cross-cultural psychological research concerning EA cultures. The current concept of dialectical thinking is described in a review article written by Spencer-Rodgers et al.:

East Asians, in comparison with their Western counterparts, are more likely to expect phenomena to undergo a change from the status quo. [...] The culture and cognition literature has characterized East Asian thought as emphasizing holistic thinking and Western thought as emphasizing analytical thinking. [...] The concept of contradiction follows naturally from the concept of change. [...] For example, a person who views his or her own personality as changeable (sometimes I am extraverted and sometimes I am introverted) might be expected to also view it as comprising contradictory elements (I am both extraverted and introverted) (2010: 296-98).

Spencer-Rodgers et al. maintain that dialectical thinking may be caused by collectivistic environment in rural agrarian communities and EA religious traditions: 'Taoist, Buddhist and Confucian belief systems are thought to have reinforced holistic and dialectical worldviews among East Asians in particular' (2010: 299). Different opinions about the source of dialectical reasoning were also published: Kim and Markman showed that Koreans prefer dialectical proverbs more, when they are primed to feel larger fear of isolation and loss of social approval. The reason for their preference for dialectical proverbs could therefore be that 'East Asians are more sensitive to situations that might bring social isolation than are Westerners' (Kim and Markman 2006: 352). Another opinion is that EA reasoning styles may be caused by interdependent self-construing - the tendency to define one's identity more by social relationships and group membership than by one's unique characteristics (Varnum et al. 2010).

The problem with the concept of EA dialectical thinking is that it derives from research comparing Chinese and Americans, which was merged with later research comparing Koreans and Americans/Canadians or Japanese and Americans/Canadians on some other tasks different from the tasks used in the original 
research. Because these tasks were not the same, the conclusion that there is some consistent concept called 'dialectical thinking' equally valid for all EA cultures cannot be drawn from this research. The structure of the 2009 article by SpencerRodgers et al. can be identified as an example of this logical fault. The authors first asked a sample of Chinese and European Americans to describe 'Who am I?' and then counted contradictory responses-Chinese respondents gave more contradictory, change-oriented and holistic answers than Americans:

\begin{abstract}
Whereas Euro-Americans demonstrate a preference for direct and affirmative selfdescriptions (e.g., "I am outgoing"), Chinese frequently define the self through the negation of an opposing self-conception (e.g., "I am not shy"). ... This finding suggests that a greater amount of contradictory self-knowledge is retrieved spontaneously from memory among Chinese. (An alternative self-image must have been brought to mind for that selfimage to have been negated.)
\end{abstract}

The spontaneous self-concept was also characterized by greater change and holism among Chinese than among Euro-Americans. Chinese participants listed a greater proportion of dynamic self-statements than did Euro-Americans. Their responses reflected more recent and ongoing changes, active states of being, and anticipated, desired, and contemplated changes (Spencer-Rodgers et al. 2009: 33).

In the next study Japanese and European American participants received a set of traits from two dimensions of personality-extraversion/introversion and creativity/conventionality. The traits representing these dimensions were first presented via a computer and the participants should answer 'me' or 'not me'. Then the traits representing these dimensions were presented through a paper questionnaire and the participants were to rate from one to seven how often these traits were characteristic for them. Japanese respondents gave more contradictory responses than Americans:

As predicted, Japanese participants exhibited significantly greater simultaneous accessibility of contradictory self-knowledge than did Euro-Americans in both personality domains. These findings suggest that contradictory self-knowledge is more accessible or retrieved more efficiently from memory among members of dialectical than synthesisoriented cultures (Spencer-Rodgers et al. 2009: 36).

In the rest of the article several other tasks different from the first two studies were given to Chinese and European/Asian Americans. The authors finally concluded:

A greater amount of contradictory self-knowledge appears to be available and accessible among East Asians relative to Euro-Americans. In Study 1, Chinese participants listed, without prompting, more contradictory paired self-statements... The stimulus question "Who am I?" activated a larger body of contradictory self-knowledge among Chinese than among Euro-Americans. In Study 2, Japanese participants exhibited significantly greater simultaneous accessibility of contradictory self-beliefs (Spencer-Rodgers et al. 2009: 40). 
However, if the Chinese subjects are found to possess quality A (writing more contradictory self-descriptions) and the Japanese subjects are found to possess quality B (selecting more contradictory self-descriptions), the conclusion that Japanese, Chinese and Koreans all possess some merger of qualities A and B is not very convincing. Japanese and Koreans were not given task A (to write self-descriptions). Nevertheless, the claim that all East Asians possess some merger of qualities A and $\mathrm{B}$ is exactly what was concluded in this article.

Research about 'dialectical thinking' found that Chinese, Japanese and Koreans think differently when compared with North Americans. However, it does not mean that Chinese, Japanese and Koreans have the same thinking and reasoning styles as the 'dialectical thinking' research presented by Spencer-Rodgers's articles (2009 and 2010) assumes. It is highly likely there can be different thinking styles in Chinese, Japanese and Korean culture. When compared with North Americans, these thinking styles produce some differences, which are together interpreted as 'dialectical thinking' by Spencer-Rodgers and her colleagues. However, if thinking and reasoning styles between different EA cultures were to be compared (or if EA cultures were to be compared with something other than North America), different patterns may be found. Since research presented by Spencer-Rodgers et al. seems to assume that East Asians from one culture are fully replaceable by East Asians from another culture for the purpose of their research, possible differences between EA cultures could not found by this method. The Universal dialectical Asian seems to be another concept obstructing psychological research intended to describe differences between EA cultures.

\section{Analysis of articles published from 2007 to 2011 in Journal of Person- ality and Social Psychology and Journal of Cross-Culture Psychology}

I have shown some examples of the 'universal Asian' trend in cross-cultural psychological research. Now I will examine its presence in recently published psychology articles. I have selected two psychological journals for this analysis: one mainstream journal—Journal of Personality and Social Psychology (JPSP) published by the American Psychological Association-and one journal specialising in crosscultural psychological research-Journal of Cross-Cultural Psychology (JCCP) published by Sage and the International Association for Cross-Cultural Psychology. I have selected all articles that use samples from Chinese culture (China, Taiwan or Hong Kong), Korea and Japan or samples of (North) American (East) Asians published in these journals from 2007 to 2011 and compare some of these cultures with some other (EA or non-EA) culture or cultures. I have excluded three types of articles from this analysis: articles using only samples from one EA culture without comparing them with other samples; those using samples from several Chinese- 
speaking cultures without comparing them with samples of other than Chinesespeaking culture; and articles using samples from a large number of cultures to confirm various hypotheses without trying to interpret the results for each sample. Among the remaining articles I have analysed which samples were used and if the results were generalised to all EA cultures without testing them with samples from other cultures, or if the results were interpreted to be valid only for cultures that were included in the research.

$J P S P$ is the leading journal for research concerning personality or social psychology. It is published monthly in two volumes per year, each volume containing six issues. Volumes 92-101, published between 2007 and 2011, contain 764 research articles. Among those articles, 26 are articles comparing an EA sample or samples with sample(s) from other culture(s) and interpreting results for the samples included. JCCP is the leading psychological journal for cross-cultural comparative research. Volumes 38-42, published between 2007 and 2011, contain five to eight issues per volume. In total, 289 research articles were published in these volumes and 63 of those used an EA sample or samples to compare it with sample(s) from other culture(s).

First, I examined which samples were used as EA samples in the research published. From 26 articles published in JPSP, seven used samples from Japan, five Korean samples, six mainland Chinese samples, eight Hong Kong samples, one a sample from Taiwan; 12 articles used samples of American/Canadian Asians and two articles samples of Asians studying in the United States/Canada. Among 63 articles published in JCCP, 18 used Japanese samples, four samples from Korea, 27 samples from mainland China, five used samples from Taiwan, nine samples from Hong Kong, seven used samples of American/Canadian Asians, four used samples of Asians studying in English-speaking countries, five samples of Chinese living in English-speaking countries, two articles used samples of Korean Americans and one a sample of Japanese Americans.

If research aims to interpret a result as typical for EA, it should analyse (at least) three samples - from Korea, Japan and some Chinese culture (mainland China, Taiwan or Hong Kong) _ analysing samples of American or Canadian Asians should not be used instead of samples from people living in EA cultures. I therefore counted articles taking samples from more than one main EA culture in both of the journals analysed. Not one out of 26 articles published in JPSP from 2007 to 2011 used samples from Japan, Korea and some Chinese culture together; three combined samples from two EA cultures and a sample of East Asians in the United States/Canada, five combined samples from one EA culture and samples of American/Canadian Asians. The remaining 18 articles used samples from only one EA culture (mainland China, Taiwan and Hong Kong taken as one culture) or samples of Asians living in North America analysed together without distinguishing country 
of heritage. Even if none of the 26 articles published in JPSP used samples from all three main EA cultures, 14 of them interpreted results as typical for all East Asians.

For JCCP, none of the articles used samples from all three main EA cultures; four articles used samples from Japan and Chinese culture, one article used samples from Korea, Hong Kong and Taiwan, and six articles used sample of notdistinguished Asian Americans/Canadians or Asian students in North America together with a sample from one EA country. A further 52 articles used samples from one EA country or samples of American/Canadian Asians or Asians living in English-speaking countries, but not distinguished according to their country of heritage. Thirteen out of 63 articles published in JCCP interpreted the results as typical for all East Asians.

Furthermore, no article in either journal compared samples from one EA culture with samples from another EA culture without comparing them also with a sample or samples from outside of EA. All the analysed articles published in JPSP and $J C C P$ contained a non-EA sample; thus, 24 out of 26 articles published in JPSP contained American or Canadian samples, 21 out of these 24 articles contained European American/Canadian samples. Samples from Germany were used three times and samples from Norway, the United Kingdom (UK) and Australia two times each. Another nine countries were compared with 'East Asia' once in 24 articles analysed. In JCCP, 43 out of 63 articles scrutinised used American or Canadian samples, 17 out of these 43 samples being European American/Canadian. Seven articles used Australian or European Australian samples and five used UK samples. Together, 53 out of 63 articles published in JCCP used samples from some Englishspeaking country to compare it with EA sample(s). Six articles used German samples, three used samples from Turkey, and two samples from Cameroon, India, Indonesia, the Netherlands or New Zealand to compare with 'East Asia'. No article used France for purposes of comparison, and only one article comparing Italy or Russia with an EA country was published in JPSP or JCCP between 2007 and 2011. Despite the limited number of 'Western' countries compared with 'East Asia' in the articles examined, some of them interpreted differences as being typical for 'the West'. Nine out of the 26 articles published in JPSP and 15 out of the JCCP's 63 articles made such an interpretation.

Overall, this analysis shows that all articles published about EA cultures in the analysed journals used samples from outside of EA and therefore used an outsider view. No article compared two EA cultures from only an EA point of view. Furthermore, nearly all articles used samples from English-speaking countries. The point of view taken in these articles was hence a view emanating from Englishspeaking cultures. For JPSP this may be caused by the fact that it is a journal published by an American organisation in English. However, JCCP is an international journal which - despite being published in English — welcomes and publishes articles comparing cultures outside the English-speaking world. Describing EA cultures 
from the point of view of the United States/English-speaking countries makes psychological research about EA cultures more stereotypical and less useful for EAS.

\section{How East Asian studies can help to improve the discourse}

Haslam and Kashima (2010) have demonstrated that 64 percent of psychology articles about (not only East) Asia have a United States-based co-author. Other countries in which the most frequently participating co-authors are based are Canada, Australia and the UK. Additionally, judging from the web pages of departments of psychology at many East Asian universities, it seems that foreign-educated faculty members in many East Asian countries got their degrees almost only from Englishspeaking countries. This lack of diversity in foreign experience makes differences between cultures other than those bounded by English-speaking countries harder to understand for these scholars, for, if they have not had experience of life in some other country, they have experienced only the differences between their own culture and an English-speaking culture.

I think that lack of diversity in the comparison of EA cultures in comparative psychological research is caused by the lack of diversity in the cultural background of research teams conducting this research. I challenge the research methodology introduced by Yang (2000) that neglects the importance of researchers' diverse cultural backgrounds. Yang presented the idea of constructing indigenous monocultural psychologies first, and then of constructing cross-cultural psychology through joint research by researchers from different cultures, who will discuss the differences between their cultures among each other. From Yang's point of view, it is enough for a scholar to understand his own culture in order to be able to do cross-cultural research together with someone who also understands only his own culture. Even if neither of them has any real experience of the differences between these cultures, they will still be able to produce good quality cross-cultural research. I will show the inappropriateness of this approach by an example from quantitative research. Let us imagine the variables $A, B$ and $C$ with possible values from 0 to 10 , culture $\Theta$ with average values of $\mathrm{A}=9, \mathrm{~B}=7$ and $\mathrm{C}=3$, and culture $\Omega$ with average values of $\mathrm{A}=7$, $\mathrm{B}=9$ and $\mathrm{C}=0$. Two scholars from cultures $\Theta$ and $\Omega$ discussing differences between their cultures would find variables A and B worth investigating. Nevertheless, the difference represented by $\mathrm{C}$ is perhaps the most important-but the scholar from culture $\Omega$ does not know the behaviour referred to by $\mathrm{C}$, and the scholar from culture $\Theta$ does not consider it an important topic to discuss. The problem would be more complicated if the difference were not only in variables, but in the structures or concepts that should be used - a procedural knowledge of culture is not semantic knowledge and it can be hard to formulate what it is actually that constitutes that culture (Fiske 2002). Yang (2000) suggests that scholars from both cultures involved should 
conduct qualitative research about a chosen theme and then develop quantitative methods. However, the theme is already chosen and qualitative research would be unlikely to discover problems not included in the theme. Scholars without experience of the difference between their cultures would therefore be unlikely to find what constitutes the difference. The more diverse the cultural background of the research team is, the better will be the quality of cultural comparison made by this team.

I suggest that EAS scholars from other than English-speaking countries may enrich psychological research comparing different EA cultures by conducting this research together with psychologists. EAS scholars may help the development of comparative psychological research by offering their networks of contacts in different EA countries to colleagues in psychology departments. If psychologists from more diverse destinations conducted more comparative research with multiple countries in the EA region, psychology research in the area would improve in two ways. First, it would lead to comparisons of EA cultures with something other than English-speaking countries - which might well lead to new findings about EA cultures themselves. Second - and maybe more important for EAS - it would increase the number of psychology studies comparing EA cultures with other EA cultures.

EAS scholars might contact psychologists from their universities and discuss with them how the research that psychologists conduct could differ in EA cultural contexts. If the EAS scholar meets a psychologist using quantitative methods, ${ }^{6}$ for example, he could help the psychologist to understand the cultures the EAS scholar is expert in. Secondly, the two scholars might discuss the possibility of testing a theory which is in the psychologist's area of expertise in the EA countries with which the EAS scholar is familiar. The usual approach in quantitative research is to translate and back-translate the questionnaires or other methods used. EAS scholars could manage these translations. Since methods used in quantitative research (experiments or questionnaires) can usually be administered by a person without psychology training, the EAS scholar's acquaintances in EA countries could administer questionnaires to individuals or otherwise organise the experiment. The psychologist could then analyse the data and both scholars would discuss the interpretation of the findings and their implications. If the co-operation were long term, the EAS scholar would gain familiarity with the psychology theories in the field and formulate theories suitable for EA reality for himself or herself.

6 If the psychologist uses qualitative methods in his or her research, I cannot give any simple suggestion due to the diversity of qualitative approaches. Since these approaches are often specific to the concrete case, involved researchers would possibly have to develop their own method of how to conduct the research they wish to do. 


\section{Conclusion}

I have shown some examples of the 'universal Asian' trend in cross-cultural psychological research. I have selected two psychological journals for this analysis: one mainstream journal-Journal of Personality and Social Psychology, published by the American Psychological Association-and one journal specialising in crosscultural psychological research-Journal of Cross-Cultural Psychology, published by Sage and the International Association for Cross-Cultural Psychology. I have selected all articles that use samples from Chinese culture (China, Taiwan or Hong Kong), Korea, Japan or samples of (North) American (East) Asians published in these journals between 2007 and 2011, and that compare some of these cultures with other (EA or non-EA) culture or cultures. I have excluded three types of research approaches from this analysis: research using only samples from one EA culture without comparing it with other samples, research using samples from several Chinese-speaking cultures without comparing them with other than the Chinesespeaking culture, and research using samples from a large number of cultures to confirm some hypotheses without trying to interpret the results for each sample. Among the remaining articles I have analysed which samples were used and if the results were generalised to all EA cultures without testing them with samples from other cultures or if the results were interpreted to be valid only for cultures included in the research.

The role of EAS scholars is vital to the involvement of psychologists in EArelated research. Many EA psychologists see their goal as conducting research about the United States, publishing in American journals and getting a job at an American university — what Matsumoto calls their 'gold standard for comparison' (2007: 46), so they are not motivated to co-operate with psychologists from other places than the United States and English-speaking countries. I suggest that EAS scholars contact psychologists from their universities, identify interesting topics for comparisons, develop methods appropriate for such comparisons and jointly undertake research. This would lead to an improved understanding about differences in psychology in the EA region. 


\section{REFERENCES}

Cappelli, Peter. "A Cautionary View of Construct Validity.” In Human Resource Management Review, 22/2, 2012, pp. 149-151

Chentsova-Dutton, Yulia E., and Jeanne L. Tsai. "Self-Focused Attention and Emotional Reactivity: The Role of Culture." In Journal of Personality and Social Psychology, 98/3, 2010, pp. 507-519

Fiske, Alan Page. "Using Individualism and Collectivism to Compare Cultures - A Critique of the Validity and Measurement of the Constructs: Comment on Oyserman et al. (2002)." In Psychological Bulletin, 128/1, 2002, pp. 78-88

Haslam, Nick, and Yoshihisa Kashima. "The Rise and Rise of Social Psychology in Asia: A Bibliometric Analysis.” In Asian Journal of Social Psychology, 13/3, 2010, pp. 202-207

Hofstede, Geert. Culture's Consequences: International Differences in Work-Related Values. Beverly Hills: Sage, 1980

Hong, Ying-Yi. “A Dynamic Constructivist Approach to Culture: Moving From Describing Culture to Explaining Culture.” In Understanding Culture: Theory, Research and Application, edited by Robert S. Wyer, Chi-Yue Chiu and Ying-Yi Hong. New York: Psychology Press, 2009 , pp. 3-23

Kim, Kyungil, and Arthur B. Markman. "Differences in Fear of Isolation as an Explanation of Cultural Differences: Evidence from Memory and Reasoning." In Journal of Experimental Social Psychology, 42/3, 2006, pp. 350-364

Kim, Min-Sun. "Our Culture, Their Culture and Beyond: Further Thoughts on Ethnocentrism in Hofstede's Discourse.” In Journal of Multicultural Discourses, 2/1, 2007, pp. 26-31

Jahoda, Gustav. "Critical Reflections on Some Recent Definitions of 'Culture'.” In Culture \& Psychology, 18/3, 2012, pp. 289-303

Liu, James H., and Shu-Hsien Liu. "Modernism, Postmodernism and Neo-Confucian Thinking: A Critical History of Paradigm Shifts and Values in Academic Psychology." In New Ideas in Psychology, 15/2, 1997, 159-178

Matsumoto, David. "Comments on the Future of Asian Social Psychology." In Asian Journal of Social Psychology, 10/1, 2007, pp. 45-47

Oyserman, Daphna, Heather M. Coon, and Markus Kemmelmeier. "Rethinking Individualism and Collectivism: Evaluation of Theoretical Assumptions and Meta-Analyses.” In Psychological Bulletin, 128/1, 2002, pp. 3-72

Oyserman, Daphna, Markus Kemmelmeier, and Heather M. Coon. "Cultural Psychology. A New Look: Reply to Bond (2002), Fiske (2002), Kitayama (2002), and Miller (2002).” In Psychological Bulletin, 128/1, 2002, pp. 110-117

Peng, Kaiping, and Richard E. Nisbett. "Culture, Dialectics, and Reasoning about Contradiction." In American Psychologist, 54/9, 1999, pp. 741-754

Spencer-Rodgers, Julie, Helen C. Boucher, Sumi C. Mori, Lei Wang, and Kaiping Peng. "The Dialectical Self-Concept: Contradiction, Change, and Holism in East Asian Cultures." In Personality and Social Psychology Bulletin, 35/1, 2009, pp. 29-44

Spencer-Rodgers, Julie, Melissa J. Williams, and Kaiping Peng. "Cultural Differences in Expectations of Change and Tolerance for Contradiction: A Decade of Empirical Research." In Personality and Social Psychology Review, 14/3, 2010, pp. 296-312

Townsend, James T. "Mathematical Psychology: Prospects for the 21st Century: A Guest Editorial.” In Journal of Mathematical Psychology, 52, 2008, pp. 269-280 
Varnum, Michael E.W., Igor Grossmann, Shinobu Kitayama, and Richard E. Nisbett. "The Origin of Cultural Differences in Cognition: The Social Orientation Hypothesis." In Current Directions in Psychological Science, 19/1, 2010, pp. 9-13

Yang, Kuo-Shu. "Monocultural and Cross-Cultural Indigenous Approaches: The Royal Road to Development of a Balanced Global Psychology.” In Asian Journal of Social Psychology, 3/3, 2000, pp. 241-263

Yeung, Victoria Way Lan, and Yoshihisa Kashima. "Culture and Stereotype Communication: Are People From Eastern Cultures More Stereotypical in Communication?" In Journal of CrossCultural Psychology, 43/3, 2012, pp. 446-463 